\title{
Characteristics and control mechanisms of coalbed permeability change in various gas production stages
}

\author{
Da-Zhen Tang ${ }^{1,2} \cdot$ Chun-Miao Deng ${ }^{1,2}$ - Yan-Jun Meng ${ }^{1,2} \cdot$ Zhi-Ping $\mathrm{Li}^{1,2}$. \\ Hao $\mathrm{Xu}^{1,2} \cdot$ Shu $\mathrm{Tao}^{1,2} \cdot$ Song $\mathrm{Li}^{1,2}$
}

Received: 11 May 2015/Published online: 16 September 2015

(c) The Author(s) 2015. This article is published with open access at Springerlink.com

\begin{abstract}
According to dimensionless analysis of the coalbed methane (CBM) production data of Fanzhuang block in southern Qinshui basin, the dimensionless gas production rate is calculated to quantitatively divide the CBM well production process into four stages, i.e., drainage stage, unstable gas production stage, stable gas production stage, and gas production decline stage. By the material balance method, the coal reservoir permeability change in different stages is quantitatively characterized. The characteristics and control mechanisms of change in coalbed permeability (CICP) during different production stages are concluded on five aspects, i.e., permeability trend variation, controlling mechanism, system energy, phase state compositions, and production performance. The study reveals that CICP is characterized by first decline, then recovery, and finally by increase and is controlled directly by effective stress and matrix shrinkage effects. Further, the duration and intensity of the matrix shrinkage effect are inherently controlled by adsorption and desorption features.
\end{abstract}

Keywords Production stage - Coalbed methane Permeability $\cdot$ Dynamic change $\cdot$ Control mechanism

Chun-Miao Deng

chunmiaocugb@gmail.com

1 School of Energy Resources, China University of Geosciences, Beijing 100083, China

2 Coal Reservoir Laboratory of National Engineering Research Center of Coalbed Methane Development \& Utilization, Beijing 100083, China

Edited by Xiu-Qin Zhu

\section{Introduction}

Coalbed methane (CBM) is one of the most significant energy resources in the unconventional gas field. It has been developed successfully and commercially in the southern Qinshui basin and on the east edge of the Ordos basin in China (Tao et al. 2014; Meng et al. 2014b; Feng et al. 2014; Li et al. 2015). CBM development geology has become a research topic recently (Qin et al. 2014; Liu et al. 2010). As reported by many researchers, coal reservoir permeability is one of the key factors influencing the productivity of CBM wells (Song et al. 2012; Li et al. 2014; Fan et al. 2014). Thus, research on real-time quantitative prediction of characteristics of CICP during different CBM production stages has significant impacts upon the development and deployment, management of production, and productivity prediction of CBM fields in China. Many researchers have carried out studies on the theoretical model calculation and experimental simulation of CICP (Shi and Durucan 2005; Palmer 2009; Mazumder et al. 2012; Tao et al. 2012; Xu et al. 2014). However, so far the breakthrough of real-time monitoring and prediction of dynamic CICP has not been made, but it has great instructive meaning for CBM production. There is still an argument on the scheme of CBM well production stages division and their defined principles. In this paper, the production stages of CBM wells are quantitatively divided by the dimensionless analysis method, and the values of dynamic CICP in different CBM production stages are calculated by the material balance method based on production data. Finally, characteristics and control mechanisms of CICP during various stages are summarized on five aspects, including the permeability variation trend, controlling mechanism, system energy, phase state compositions, and the dynamic production. 


\section{CBM well production stages division}

There are two main schemes for dividing the CBM well production stages as follows: (1) Four stages are divided based on the characteristics of the change in fluid phase, including saturated single-phase flow of water, unsaturated single-phase flow of water, two-phase flow of gas and water, and single-phase flow of gas stages (Ni et al. 2010). (2) Five stages, including dewatering, pressure hold, pressure control, high and stable yield, and depletion stages, are classified based on the in situ pressure change characteristics, such as bottom-hole flowing pressure, desorption pressure, and strata pressure (Qin et al. 2011; Li et al. 2011). The former scheme is more scientific and reasonable in theory than the latter one, but the unsaturated single-phase flow of water and single-phase flow of gas stages are difficult to distinguish in practical production. The latter scheme is more precise and practicable than the former one, but it has a relatively weak foundation in theory and the great influence of production control factors makes it difficult to be widely used.

Generally, CBM production curves are characterized by gas production changing over time, that is, the process from no gas production, start of gas production, rise of gas production, reaching a peak of gas production, decline of gas production, to gas depletion. If the CBM production stages are divided by gas production rate, then gas production data can be directly used for division of stages. This division method is feasible in practice and theory. Therefore, this paper proposes a new four-stage division scheme based on gas production status, i.e., drainage stage, unstable gas production stage, stable gas production stage, and gas production decline stage. How to define the dividing points becomes a key problem once the classification scheme is determined. Dimensionless treatment of production data is widely used to conventional oil/gas and CBM production analysis due to the elimination of the influence of dimension on data analysis (Clarkson et al. 2008; Aminian and Ameri 2009; Freeman et al. 2013). Hence, this paper uses the dimensionless method to process gas and water production data. And the dimensionless gas production rate is chosen as an appropriate parameter, which indicates the relative change in gas and water production rates.

\subsection{Dimensionless gas and water production}

The dimensionless gas production is defined as the ratio of gas production to the peak gas production, that is

$N_{\mathrm{gD}}=\frac{q_{\mathrm{g}}}{q_{\mathrm{gmax}}}$,

where $N_{\mathrm{gD}}$ is the dimensionless gas production; $q_{\mathrm{g}}$ is the CBM well gas production, $\mathrm{m}^{3} /$ days; and $q_{\text {gmax }}$ is the peak gas production, $\mathrm{m}^{3} /$ days.
Similarly, dimensionless water production is defined as the ratio of water production to peak water production, that is

$N_{\mathrm{wD}}=\frac{q_{\mathrm{w}}}{q_{\mathrm{wmax}}}$,

where $N_{\mathrm{wD}}$ is the dimensionless water production; $q_{\mathrm{w}}$ is the CBM well water production, $\mathrm{m}^{3} /$ days; and $q_{\mathrm{wmax}}$ is the peak water production, $\mathrm{m}^{3} /$ days.

By dimensionless treatment, the value of gas or water production is limited in a certain range from 0 to 1 $\left(N_{\mathrm{gD}}, N_{\mathrm{wD}} \in[0,1]\right)$. For CBM wells with long production history, the peak gas or water production value can be obtained directly from their production data. While, for wells with a short history, these parameters can refer to analogous wells that have a long history and similar geological and engineering conditions.

\subsection{Dimensionless gas production rate}

The dimensionless gas production rate is defined as the ratio of dimensionless gas production to the sum of dimensionless gas production and dimensionless water production, that is

$\eta_{\mathrm{gD}}=\frac{N_{\mathrm{gD}}}{N_{\mathrm{gD}}+N_{\mathrm{wD}}}=\frac{\frac{q_{\mathrm{g}}}{q_{\mathrm{g} \max }}}{\frac{q_{\mathrm{g}}}{q_{\mathrm{g} \max }}+\frac{q_{\mathrm{w}}}{q_{\mathrm{w} \max }}}$,

where $\eta_{\mathrm{gD}}$ is the dimensionless gas production rate.

It can be seen from Eq. (3) that the value of the dimensionless gas rate is also between 0 and 1 . According to the value of dimensionless gas rate, the CBM production process can be divided into four stages. In drainage stage, there is only water produced until the gas starts coming out. If we set $\eta_{1}$ as dimensionless gas rate of the time point at which gas begins to produce, then the dimensionless gas rate ranges from 0 to $\eta_{1}$ at this stage. It is worthy to note that each production well has different $\eta_{1}$ due to the various durations of the drainage stage. In the unstable gas production stage, the production of gas increases gradually from zero, and water production tends to decrease. The corresponding dimensionless gas rate also increases gradually during this stage. If we set $\eta_{2}$ as dimensionless gas rate at the time point when gas production begins to stabilize, then the dimensionless gas rate ranges from $\eta_{1}$ to $\eta_{2}$ in this stage. Generally, the dimensionless gas rate of this stage is larger than 0.5 . In stable gas production stage, the production of gas remains at a high level with slight fluctuations. And the corresponding water production remains at a low level. If we set $\eta_{3}$ as dimensionless gas rate at the point when gas production begins to decline, then the dimensionless gas rate varies from $\eta_{2}$ to $\eta_{3}$ in this stage. In gas production decline stage, gas production tends to decline and water production 
decreases gradually from a very low level to 0 . The dimensionless gas rate ranges from $\eta_{3}$ to 1 in this stage.

\subsection{CBM well production stages division for the southern Qinshui basin}

Fifteen CBM wells with stable and continuous production were selected from the Fanzhuang block of the southern Qinshui basin (China) for study of the CBM well production stages division. The basic production data of these 15 CBM wells are shown in Table 1 . The production history of wells $\mathrm{W} 1-\mathrm{W} 10$ is relatively short, at about 330-770 days. W11-W15 have a longer production history than W1-W10, at about 2000 days. Besides, W4, W5, W6, W9, W14, and W15 are high-productivity wells.

By dimensionless treatment of the production data of 15 wells, the dimensionless gas and water production and the dimensionless gas production rate are calculated for each well. Production stages are divided for each well by the value of dimensionless gas production rate (Table 2). The original production curve and dimensionless production curve of W14 are shown in Figs. 1 and 2, respectively. All of the 15 wells have experienced drainage stage, unstable gas production stage, and stable gas production stage. Eight of the 15 wells have reached the gas production decline stage. In the drainage stage, the dimensionless gas production rate ranges from 0.107 to 0.426 , which is related to the ratio of initial gas production to the highest gas production. Generally, the value of the dimensionless gas production rate of high-productivity wells is less than that of the low-productivity wells. The dimensionless gas production rate varies from 0.547 to 0.683 at the end of the unstable gas production stage, and from 0.713 to 0.909 at the end of the stable gas production stage.

\section{Calculation of CICP at each stage}

During the CBM production process, the coal reservoir permeability changes all the time. The CICP has an important influence on $\mathrm{CBM}$ production and on the adjustment of future CBM development plans. So, it is vital to understand the characteristics of CICP at each stage. Currently, there is no direct method to obtain coal reservoir permeability during the gas production process because almost no productivity test is applied in this process. However, the material balance method, one of the commonly used techniques in dynamic analysis in the reservoir engineering field, is applied very well in CBM reservoirs (King 1993; Lai et al. 2013). Based on the data of gas and water production, and relevant parameters of reservoir and fluid, the CICP during development process can be calculated by this method. Hence, in this paper we calculate the reservoir permeability at each production stage of CBM wells in the southern Qinshui basin (Table 3; Fig. 3). The calculations are based on the original production data, considering the effects of effective stress and matrix shrinkage.

Table 1 Basic production data of 15 CBM wells in the southern Qinshui basin (China)

\begin{tabular}{|c|c|c|c|c|c|c|c|c|c|}
\hline $\begin{array}{l}\text { Well } \\
\text { name }\end{array}$ & $\begin{array}{l}\text { Total } \\
\text { pro-t, } \\
\text { days }\end{array}$ & $\begin{array}{l}\text { Drainage } \\
\text { time, days }\end{array}$ & $\begin{array}{l}\text { Gas pro- } \\
\mathrm{t} \text {, days }\end{array}$ & $\begin{array}{l}\text { Total gas } \\
\text { pro- }, 10^{3} \mathrm{~m}^{3}\end{array}$ & $\begin{array}{l}\text { Total water } \\
\text { pro- }, \mathrm{m}^{3}\end{array}$ & $\begin{array}{l}\text { Highest gas } \\
\text { pro-, } \mathrm{m}^{3} / \text { days }\end{array}$ & $\begin{array}{l}\text { Highest water } \\
\text { pro- }, \mathrm{m}^{3} / \text { days }\end{array}$ & $\begin{array}{l}\text { Average gas } \\
\text { pro- }, \mathrm{m}^{3} / \text { days }\end{array}$ & $\begin{array}{l}\text { Average gas } \\
\text { pro- }, \mathrm{m}^{3} / \text { days }\end{array}$ \\
\hline W1 & 407 & 82 & 325 & 18.036 & 617.1 & 1055 & 5.0 & 554.9 & 1.52 \\
\hline W2 & 336 & 129 & 207 & 28.324 & 1220.0 & 2123 & 6.3 & 1368.3 & 3.63 \\
\hline W3 & 336 & 128 & 208 & 20.678 & 1992.4 & 1679 & 10.5 & 1615.5 & 5.93 \\
\hline W4 & 770 & 128 & 642 & 190.159 & 1024.8 & 5806 & 7.1 & 2962.0 & 1.33 \\
\hline W5 & 770 & 52 & 718 & 175.009 & 455.1 & 4488 & 4.0 & 2437.4 & 0.59 \\
\hline W6 & 580 & 126 & 454 & 144.527 & 1455.9 & 5144 & 10.2 & 3183.4 & 2.51 \\
\hline W7 & 574 & 116 & 458 & 92.667 & 845.5 & 2714 & 4.2 & 2023.3 & 1.47 \\
\hline W8 & 771 & 74 & 697 & 124.676 & 705.8 & 4122 & 5.7 & 1788.8 & 0.92 \\
\hline W9 & 749 & 180 & 417 & 136.752 & 809.5 & 4235 & 11 & 2960.0 & 1.36 \\
\hline W10 & 409 & 186 & 223 & 26.135 & 451.5 & 2468 & 3.4 & 1171.9 & 1.10 \\
\hline W11 & 1908 & 186 & 1722 & 209.190 & 3281.8 & 2928 & 8.4 & 1214.8 & 1.72 \\
\hline W12 & 1910 & 185 & 1725 & 212.420 & 1780.6 & 1935 & 6.7 & 1231.4 & 0.93 \\
\hline W13 & 1890 & 224 & 1666 & 161.440 & 3624.7 & 1848 & 9.2 & 969.03 & 1.92 \\
\hline W14 & 1749 & 120 & 1629 & 595.010 & 2424.1 & 6344 & 8.3 & 3652.61 & 1.39 \\
\hline W15 & 1908 & 210 & 1698 & 342.870 & 10178.5 & 3272 & 9.5 & 2019.26 & 5.33 \\
\hline
\end{tabular}

pro- production, pro-t production time 
Table 2 Summary of the dimensionless gas production rate in each production stage of 15 CBM wells in the southern Qinshui basin

\begin{tabular}{lllll}
\hline Well name & $\begin{array}{l}\text { Drainage stage } \\
\text { Onstable gas pro-stage }\end{array}$ & $\begin{array}{l}\text { Stable gas pro-stage } \\
\eta_{2}\end{array}$ & $\begin{array}{l}\text { Gas pro-decline stage } \\
\eta_{3}\end{array}$ \\
\hline W1 & 0 & 0.174 & 0.607 & 0.904 \\
W2 & 0 & 0.339 & 0.606 & - \\
W3 & 0 & 0.321 & 0.547 & - \\
W4 & 0 & 0.153 & 0.637 & - \\
W5 & 0 & 0.127 & 0.646 & - \\
W6 & 0 & 0.107 & 0.621 & - \\
W7 & 0 & 0.353 & 0.659 & - \\
W8 & 0 & 0.172 & 0.683 & 0.909 \\
W9 & 0 & 0.124 & 0.627 & 0.866 \\
W10 & 0 & 0.328 & 0.651 & - \\
W11 & 0 & 0.393 & 0.635 & 0.713 \\
W12 & 0 & 0.426 & 0.652 & 0.844 \\
W13 & 0 & 0.406 & 0.607 & 0.867 \\
W14 & 0 & 0.238 & 0.632 & 0.897 \\
W15 & 0 & 0.279 & 0.621 & 0.891 \\
\hline
\end{tabular}

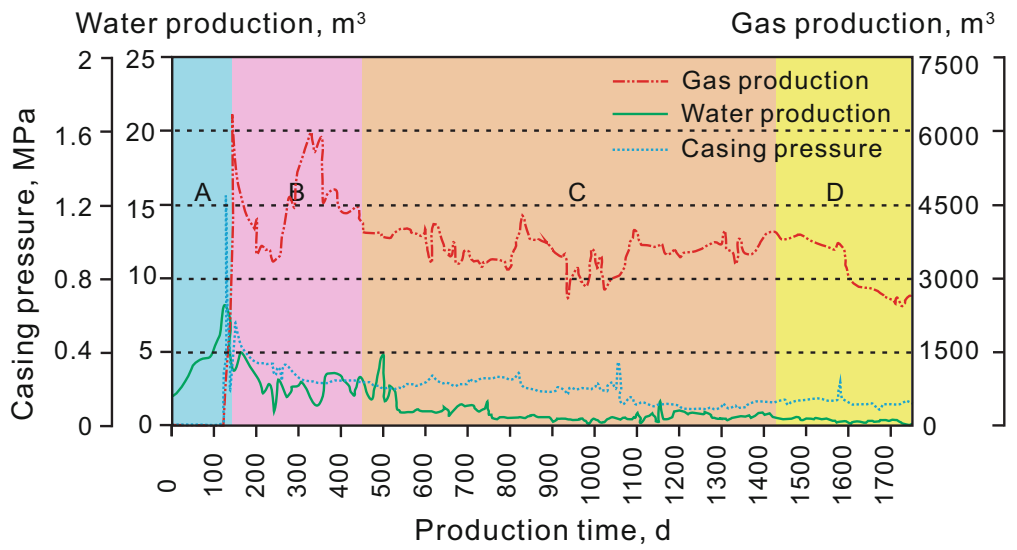

Fig. 1 Production curves of CBM well W14 at southern Qinshui basin, including gas and water production curves and reservoir pressure curve. $a$ Drainage stage, $b$ unstable gas production stage, $c$ stable gas production stage, and $d$ gas production decline stage

A number of important characteristics of CICP can be found from the calculated results and are summarized below: (1) In the drainage stage, the permeability of each well decreases, and CICP rate ranges from $-0.92 \%$ to $-0.11 \%$, with an average value of $-0.56 \%$, and CICP rate per unit pressure reduced (CICPR/PR) ranges from $-8.68 \%$ to $-4.30 \% / \mathrm{MPa}$, with an average value of $-7.82 \% / \mathrm{MPa}$. (2) In the unstable gas production stage, CICP rate ranges from $-20.2 \%$ to $-0.41 \%$, with an average value of $-8.53 \%$, and CICPR/PR ranges from $-8.43 \%$ to $-4.00 \% / \mathrm{MPa}$, with an average value of $-6.94 \% / \mathrm{MPa}$. During this stage, the reservoir permeability declines dramatically although some gas has been desorbed out. (3) In the stable gas production stage, the permeability change rate ranges from -5.53 to -0.15 , with an average value of $-2.73 \%$, and CICPR/PR ranges from $-8.43 \% / \mathrm{MPa}$ to

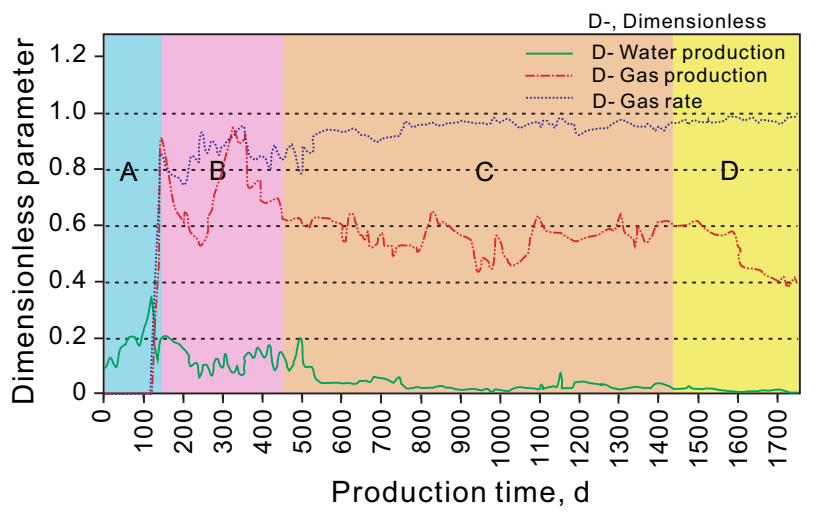

Fig. 2 Dimensionless production curves of CBM well W14 at southern Qinshui basin, including dimensionless gas production, water production, and gas production rate. $A$ drainage stage, $B$ unstable gas production stage, $C$ stable gas production stage, and $D$ gas production decline stage 
$-1.46 \% / \mathrm{MPa}$, with an average value of $-5.13 \% / \mathrm{MPa}$. (4) In the gas production decline stage, five wells (from W11 to W15) show a relatively full decline stage as they have a long production history, but other wells show no decline or reaching an early decline stage. There are no obvious features of permeability change in three wells (W11, W12, and W13), due to applying production-enhanced measurement. Two high-productivity wells(W14 and W15) have a relatively long duration of their gas production decline stage, and their CICP does not decrease but increases in this stage, with CICP increasing by $0.78 \%$ for W14 and $0.45 \%$ for W15. A similar trend is found for the CICPR/PR of wells W14 and W15, with CICPR/PR increasing by 2.53 and $1.15 \% / \mathrm{MPa}$, respectively.

By analyzing the calculated results of CICP of 15 wells, it is found that CICP decreases during the stages from drainage stage to stable gas production stage. Moreover, the CICP rate and the reduction value of permeability are the largest in unstable gas production stage. Similarly, the CICPR/PR and the value of permeability per unit pressure reduced decrease gradually during the stages from drainage stage to stable gas production stage, and the reduction of permeability is the largest in the drainage stage. With the progress of production, the permeability reduction phenomenon disappears gradually, and permeability can be recovered to the original level or even larger when production process reaches the gas production decline stage.

\section{Characteristics and mechanisms of CICP in production stages}

Some studies have demonstrated that effective stress and matrix shrinkage would cause the phenomenon of "decrease first and then increase" in coal reservoir permeability (Shi and Durucan 2005; Palmer 2009; Mazumder et al. 2012). However, this conclusion lacks verification with production data and systematic studies of control mechanisms of permeability. Therefore, this paper verifies the characteristics of dynamic change of permeability in high-rank coal reservoirs on the basis of production data. It also explains and concludes the characteristics and mechanisms of CICP during production stages from five aspects, i.e., the permeability variation trend, controlling mechanism, system energy, phase composition, and the production performance (Table 4; Fig. 4).

During the CBM production, phase compositions of the fluid change gradually from single-phase water to twophase gas and water, and then to single-phase gas flow. Water production declines gradually over time, and gas production shows a trend of "start—rise-stable-decline" of gas production. With increasing cumulative gas production, the matrix shrinkage effect plays a more and more important role in the increase of the permeability. Thus, the largest reduction value of CICPR/PR occurs in the drainage stage. After this stage, the reduction of

Table 3 Summary of calculation results of permeability change in each stage of 15 CBM wells in southern Qinshui basin

\begin{tabular}{|c|c|c|c|c|c|c|c|c|c|c|c|c|}
\hline \multirow{2}{*}{$\begin{array}{l}\text { Well } \\
\text { name }\end{array}$} & \multicolumn{3}{|c|}{ Drainage stage } & \multicolumn{3}{|c|}{ Unstable gas pro-stage } & \multicolumn{3}{|c|}{ Stable gas pro-stage } & \multicolumn{3}{|c|}{ Gas pro-decline stage } \\
\hline & $\begin{array}{l}\Delta p \\
\mathrm{MPa}\end{array}$ & $\varphi k, \%$ & $\begin{array}{l}\xi k, \% / \\
\mathrm{MPa}\end{array}$ & $\begin{array}{l}\Delta p \\
\mathrm{MPa}\end{array}$ & $\varphi k, \%$ & $\begin{array}{l}\xi k, \% / \\
\mathrm{MPa}\end{array}$ & $\begin{array}{l}\Delta p \\
\mathrm{MPa}\end{array}$ & $\varphi k, \%$ & $\begin{array}{l}\xi k, \% / \\
\mathrm{MPa}\end{array}$ & $\begin{array}{l}\Delta p \\
\mathrm{MPa}\end{array}$ & $\varphi k, \%$ & $\begin{array}{l}\xi k, \% / \\
\mathrm{MPa}\end{array}$ \\
\hline W1 & 0.069 & -0.600 & -8.662 & 0.275 & -2.320 & -8.430 & 0.275 & -2.320 & -8.430 & - & - & - \\
\hline W2 & 0.094 & -0.814 & -8.645 & 0.703 & -5.747 & -8.171 & - & - & - & - & - & - \\
\hline W3 & 0.106 & -0.919 & -8.638 & 0.643 & -5.264 & -8.192 & - & - & - & - & - & - \\
\hline W4 & 0.090 & -0.778 & -8.639 & 3.059 & -20.18 & -6.596 & - & - & - & - & - & - \\
\hline W5 & 0.040 & -0.350 & -8.677 & 2.893 & -19.65 & -6.793 & - & - & - & - & - & - \\
\hline W6 & 0.057 & -0.494 & -8.667 & 2.563 & -17.96 & -7.008 & - & - & - & - & - & - \\
\hline W7 & 0.058 & -0.501 & -8.666 & 1.804 & -13.58 & -7.524 & - & - & - & - & - & - \\
\hline W8 & 0.057 & -0.491 & -8.667 & 2.246 & -16.24 & -7.230 & 0.026 & -0.145 & -5.671 & - & - & - \\
\hline W9 & 0.097 & -0.841 & -8.643 & 1.477 & -11.35 & -7.686 & 0.907 & -5.527 & -6.095 & - & - & - \\
\hline W10 & 0.073 & -0.633 & -8.657 & 0.580 & -4.800 & -8.270 & - & - & - & - & - & - \\
\hline W11 & 0.144 & -0.619 & -4.297 & 0.103 & -0.412 & -3.997 & 0.21 & -0.756 & -3.601 & 0.088 & -0.284 & -3.233 \\
\hline W12 & 0.043 & -0.318 & -7.398 & 0.270 & -1.907 & -7.061 & 0.649 & -4.196 & -6.465 & 0.186 & -1.114 & -5.992 \\
\hline W13 & 0.081 & -0.594 & -7.339 & 0.165 & -1.177 & -7.132 & 0.438 & -2.967 & -6.774 & 0.535 & -3.269 & -6.110 \\
\hline W14 & 0.018 & -0.105 & -5.807 & 0.872 & -4.107 & -4.710 & 1.408 & -2.055 & -1.460 & 0.308 & 0.779 & 2.532 \\
\hline W15 & 0.050 & -0.290 & -5.805 & 0.619 & -3.249 & -5.249 & 1.493 & -3.844 & -2.574 & 0.395 & 0.454 & 1.149 \\
\hline Average & 0.071 & -0.556 & -7.813 & 1.218 & -8.530 & -6.937 & 0.676 & -2.726 & -5.133 & 0.302 & - & - \\
\hline
\end{tabular}

$\Delta p$ cumulative pressure decline, $\varphi k$ CICP rate, $\xi k$ CICPR/PR, "-" minus sign indicates that permeability decreases comparing to the original value, "_" no data 
CICPR/PR will decrease or become negative. The CICP rate changes with the production time, water production, and gas production in different production stages. Generally, during the unstable gas production stage, water production is relatively large and gas production relatively small. Besides, the duration of this stage is longer than that of drainage stage. Therefore, the largest value of reduction in permeability appears in this stage. Different types of CBM production wells have various characteristics of CICP. For wells with similar production time, the effect of matrix shrinkage is stronger in high-productivity wells than in low-productivity wells. Hence, the extent of recovery and improvement of permeability is better in high-productivity wells than in low-productivity wells.

In brief, the effective stress and the coal matrix shrinkage effects are the dominant mechanisms of CICP during CBM development process. Furthermore, the duration and degree of these two effects are the direct reasons for permeability change during different production stages. Besides, the duration and degree of matrix

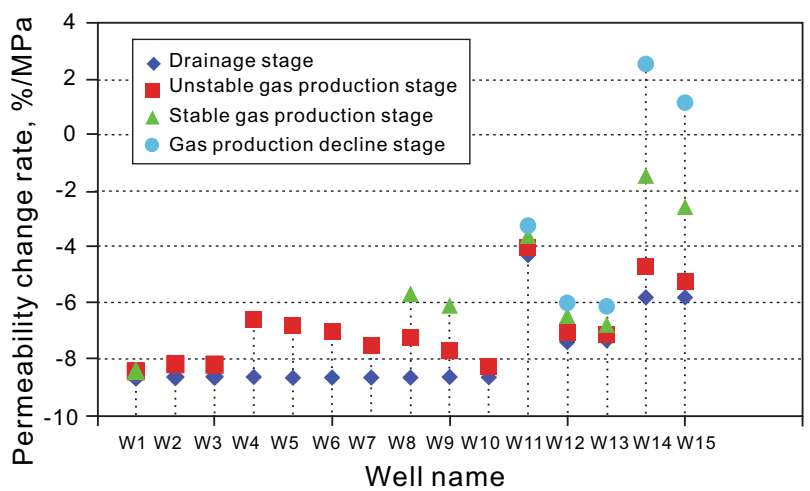

Fig. 3 CICP rate in each production stage of southern Qinshui basin shrinkage, controlled by adsorption and desorption performance (CBM desorption efficiency), are direct controlling factors for the recovery of the coal reservoir permeability (Meng et al. 2014a). Phase composition provides a preliminary basis for coal reservoir permeability stage division. Dynamic production data provide a basis for the calculation of permeability of different stages.

\section{Conclusion}

(1) Using dimensionless gas production rate, CBM production process is quantitatively divided into four stages, i.e., drainage stage, unstable gas production stage, stable gas production stage, and gas production decline stage. Calculation of dimensionless parameters for the Fanzhuang block indicates that dimensionless gas production rate ranges from 0.107 to 0.426 at the end of the drainage stage and the high-productivity wells generally have smaller dimensionless gas production rates than the lowproductivity wells. The dimensionless gas production rate ranges from 0.547 to 0.683 and from 0.713 to 0.909 , at the end of unstable gas production and stable gas production stages, respectively.

(2) The case study of the CICP during production stages of the Fanzhuang block shows that the permeability decreases in drainage stage, unstable gas production stage, and stable gas production stage. The highest permeability change rate and reduction of permeability are found in unstable gas production stage. The largest reduction of CICPR/PR occurs in drainage stage. With the progress of production, permeability reduction is gradually improved, and the permeability can be recovered to the original

Table 4 Summary of characteristics of CICP, control mechanisms, systematic energy, phase compositions, and production performance during production stages

\begin{tabular}{|c|c|c|c|c|c|}
\hline $\begin{array}{l}\text { Production } \\
\text { stage }\end{array}$ & $\begin{array}{l}\text { Permeability change } \\
\text { trend }\end{array}$ & Controlling mechanism & System energy & $\begin{array}{l}\text { Phase } \\
\text { composition }\end{array}$ & Pro-performance \\
\hline $\begin{array}{l}\text { Drainage } \\
\text { stage }\end{array}$ & Declines gradually & Effective stress effect & $\begin{array}{l}\text { Inefficient and } \\
\text { slow desorption }\end{array}$ & $\begin{array}{l}\text { Single-phase } \\
\text { water flow }\end{array}$ & No gas production \\
\hline $\begin{array}{l}\text { Unstable gas } \\
\text { pro-stage }\end{array}$ & $\begin{array}{l}\text { Declines in total, but } \\
\text { recovers gradually }\end{array}$ & $\begin{array}{l}\text { Effective stress effect and matrix } \\
\text { shrinkage effect }\end{array}$ & $\begin{array}{l}\text { Rapid and } \\
\text { sensitive } \\
\text { desorption }\end{array}$ & $\begin{array}{l}\text { Gas-water two- } \\
\text { phase flow }\end{array}$ & $\begin{array}{l}\text { Gas production rise, } \\
\text { unstable }\end{array}$ \\
\hline $\begin{array}{l}\text { Stable gas } \\
\text { pro-stage }\end{array}$ & Recovers fast & Matrix shrinkage effect & $\begin{array}{l}\text { Sensitive } \\
\text { desorption }\end{array}$ & Gas phase flow & $\begin{array}{l}\text { Gas production } \\
\text { stable }\end{array}$ \\
\hline $\begin{array}{l}\text { Gas pro- } \\
\text { decline } \\
\text { stage }\end{array}$ & $\begin{array}{l}\text { Recovers early, later } \\
\text { remain unchanged }\end{array}$ & $\begin{array}{l}\text { Early matrix shrinkage effect, later } \\
\text { effective stress effect }\end{array}$ & $\begin{array}{l}\text { Sensitive } \\
\text { desorption }\end{array}$ & $\begin{array}{l}\text { Single-phase } \\
\text { gas flow }\end{array}$ & $\begin{array}{l}\text { Gas production } \\
\text { declines gradually }\end{array}$ \\
\hline
\end{tabular}

Notes System energy division is detailed in Meng et al. (2014a) 


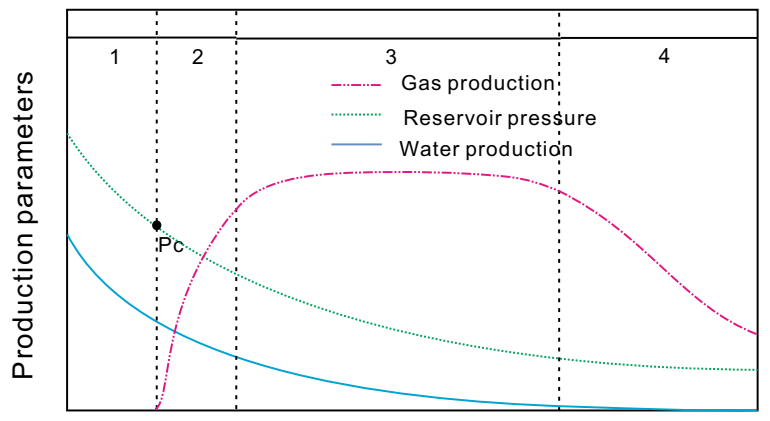

Production time
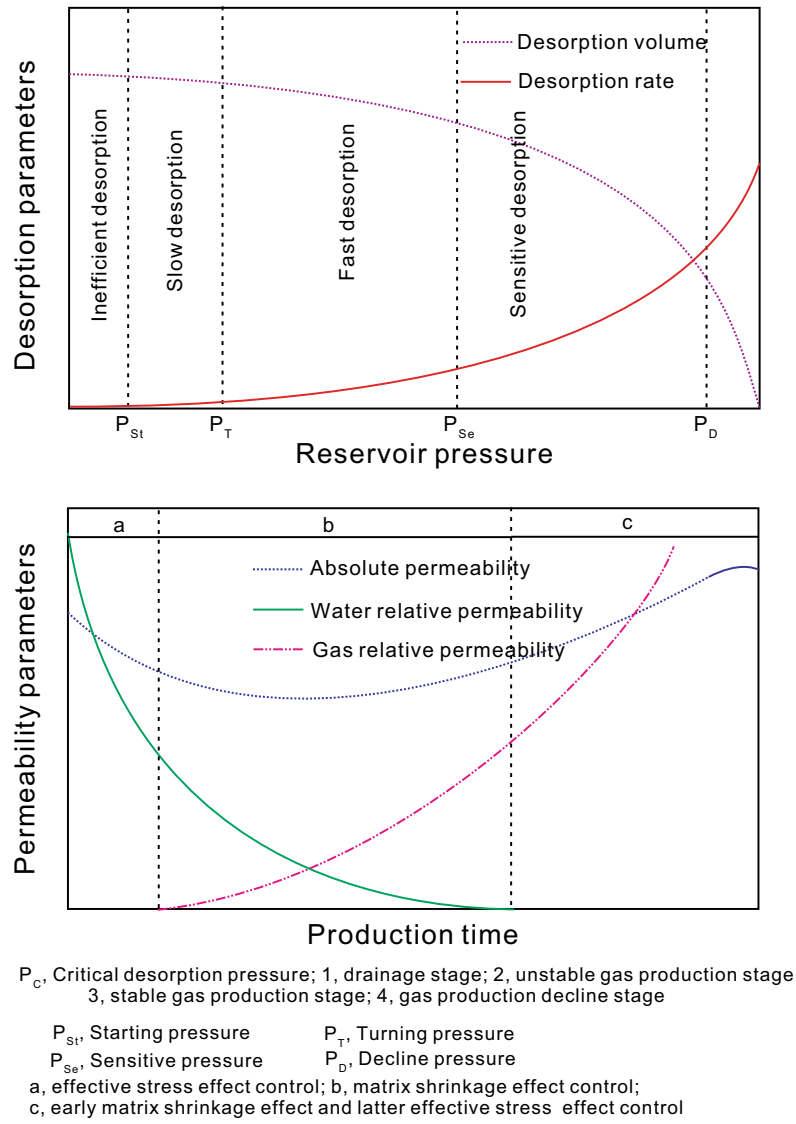

Fig. 4 Characteristics and mechanism of CBM permeability for different stages

level or even higher when production process reaches the gas production decline stage. This study indicates that the characteristics of CICP during production stages are closely related to production of gas and water and the stability of production.

(3) Characteristics of CICP are directly controlled by the duration and degree of the effective stress effect and coal matrix shrinkage effect. From the point of system energy, the duration and degree of the matrix shrinkage effect are influenced by adsorption and desorption behavior. Phase composition provides a preliminary basis for coal reservoir permeability stage division. It also indicates the changes in effective gas permeability. Production performance reflects the characteristics of production in different stages. Dynamic production data provide a basis for the calculation of the permeability at different stages, making it useful for prediction of productivity.

(4) Study of characteristics of dynamic CICP on the basis of production data provides an effective solution for a difficult problem in real-time monitoring and forecasting CICP. In addition, the related calculation method and theoretical results can be used for the deployment of CBM well development, management of production, and prediction of productivity.

Acknowledgments The authors acknowledge financial support from the various funding agencies including the Major State Basic Research Development Program of China (973 Program, 2009CB219604), the National Natural Science Foundation of China (41272175), the Key Project of the National Science \& Technology (2011ZX05034-001), and the China Scholarship Council.

Open Access This article is distributed under the terms of the Creative Commons Attribution 4.0 International License (http://crea tivecommons.org/licenses/by/4.0/), which permits unrestricted use, distribution, and reproduction in any medium, provided you give appropriate credit to the original author(s) and the source, provide a link to the Creative Commons license, and indicate if changes were made.

\section{References}

Aminian K, Ameri S. Predicting production performance of CBM reservoirs. J Nat Gas Sci Eng. 2009;1(1):25-30.

Clarkson C, Jordan C, Gierhart R, et al. Production data analysis of coalbed-methane wells. SPE Reserv Eval Eng. 2008;11(2):311-25.

Fan T, Zhang G, Cui J. The impact of cleats on hydraulic fracture initiation and propagation in coal seams. Pet Sci. 2014;11(4): 532-9.

Feng D, Deng H, Zhou Z, et al. Paleotopographic controls on facies development in various types of braid-delta depositional systems in lacustrine basins in China[J]. Geosci Front. 2014. doi:10.1016/ j.gsf.2014.03.007.

Freeman CM, Moridis G, Ilk D, et al. A numerical study of performance for tight gas and shale gas reservoir systems. J Petrol Sci Eng. 2013;108:22-39.

King GR. Material-balance techniques for coal-seam and devonian shale gas reservoirs with limited water influx. SPE Reserv Eng. 1993;8(1):67-72.

Lai F, Li Z, Fu Y, et al. A drainage data-based calculation method for coalbed permeability. J Geophys Eng. 2013;10(6):65-70.

Li M, Wang L, Cui X, et al. Output characteristics of vertical wells and dewatering control method used in Fanzhuang block of Qinshui CBM field. China Coalbed Methane. 2011;8(1):11-3 (in Chinese).

Li Y, Tang D, Xu H, et al. Geological and hydrological controls on water co-produced with coalbed methane in Liulin, eastern Ordos Basin, China. AAPG Bull. 2015;99(2):207-29. 
Li Y, Tang $\mathrm{D}, \mathrm{Xu} \mathrm{H}$, et al. In-situ stress distribution and its implication on coalbed methane development in the Liulin area, eastern Ordos basin, China. J Petrol Sci Eng. 2014;122:488-96.

Liu D, Yao Y, Cai Y, et al. Study progress on geological and dynamic evaluation of coal bed methane reservoir. Coal Sci Technol. 2010;38(11):10-6 (in Chinese).

Mazumder S, Scott M, Jiang J. Permeability increase in Bowen Basin coal as a result of matrix shrinkage during primary depletion. Int J Coal Geol. 2012;96(1):109-19.

Meng Y, Tang D, Xu H, et al. Division of coalbed methane desorption stages and its significance. Pet Explor Dev. 2014a;41(5):671-7.

Meng Y, Tang D, Xu H, et al. Geological controls and coalbed methane production potential evaluation: a case study in the Liulin area, eastern Ordos Basin, China[J]. J Nat Gas Sci Eng. 2014b;21:95-111.

Ni X, Su X, Zhang X. Coal bed methane development geology. Beijing: Chemical Industry Press; 2010 (in Chinese).

Palmer I. Permeability changes in coal: analytical modeling. Int $\mathbf{J}$ Coal Geol. 2009;77(1):119-26.

Qin Y, Li Y, Bai J, et al. Technologies in the CBM drainage and production of wells in the southern Qinshui basin with high-rank coal beds. Nat Gas Ind. 2011;31(11):22-5 (in Chinese).
Qin Y, Tang D, Liu D, et al. Geological evaluation theory and technology progress of coal reservoir dynamics during coalbed methane drainage. Coal Sci Technol. 2014;42(1):80-8 (in Chinese).

Shi JQ, Durucan S. A model for changes in coalbed permeability during primary and enhanced methane recovery. SPE Reserv Eval Eng. 2005;8(4):291-9.

Song Y, Liu S, Zhang Q, et al. Coalbed methane genesis, occurrence and accumulation in China[J]. Pet Sci. 2012;9(3):269-80.

Tao S, Tang D, Xu H, et al. Factors controlling high-yield coalbed methane vertical wells in the Fanzhuang Block, Southern Qinshui Basin[J]. Int J Coal Geol. 2014;134:38-45.

Tao S, Wang Y, Tang D, et al. Dynamic variation effects of coal permeability during the coalbed methane development process in the Qinshui Basin, China. Int J Coal Geol. 2012;93:16-22.

$\mathrm{Xu} \mathrm{H}$, Tang DZ, Tang SH, et al. A dynamic prediction model for gaswater effective permeability based on coalbed methane production data. Int J Coal Geol. 2014;121:44-52. 